\title{
Catorce nuevas especies del género Drosophila (Diptera, Drosophilidae) en el Bosque húmedo montano del Volcán Pasochoa, Pichincha, Ecuador.
}

\author{
Doris Vela ${ }^{1}$ V Violeta Rafael ${ }^{2}$ \\ Laboratorio de Genética Evolutiva. Escuela de Ciencias Biológicas, \\ Pontificia Universidad Católica del Ecuador, apartado 17-01-2184, Quito, Ecuador. \\ vrafael@puce.edu.ec, ${ }^{2}$ dorisophila@yahoo.com' \\ Recibido 1 marzo 2005, aprobado 15 junio 2005
}

\begin{abstract}
RESUMEN. En el presente estudio se describen catorce nuevas especies del género Drosophila descubiertas recientemente en el Volcán Pasochoa, las nuevas especies pertenecen a cinco grupos de especies del género 1. grupo repleta: Drosophila shuyu; 2. grupo tripunctata: Drosophila patacorona, Drosophila quillu, Drosophila ninarumi, Drosophila surucucho, Drosophila ichubamba y Drosophila urcu; 3. grupo flavopilosa: Drosophila suni, Drosophila taxohuaycu y Drosophila sisa; 4. grupo guarani: Drosophila cuscungu; 5. grupo annulimana: Drosophila yana y dos especies no agrupadas: Drosophila condormachay y Drosophila pugyu.
\end{abstract}

PALABRAS CLAVE. Ecuador, Drosophila, nuevas especies, Volcán Pasochoa.

\begin{abstract}
Fourteen new species of genus Drosophila (Diptera, Drosophilidae) in humid montane forest Pasochoa Volcano, Pichincha, Ecuador. In the present study, fourteen new species of Drosophila genus are described, all species recently were discovered in the Pasochoa Volcano, the new species belong to five Drosophila species group. 1. repleta group: Drosophila shu$y u ; 2$. tripuctata group: Drosophila patacarona, Drosophila quillu, Drosophila ninarumi, Drosophila surucucho, Drosophila ichubamba and Drosophila urcu; 3. flavopilosa group: Drosophila suni, Drosophila taxohuaycu and Drosophila sisa; 4. guarani group: Drosophila cuscungu; 5. annulimana group: Drosophila yana and two species no grouped: Drosophila condormachay and Drosophila pugyu.
\end{abstract}

KEYWORDS. Ecuador, Drosophila, new species, Pasochoa Volcano.

\section{INTRODUCCIÓN}

En trabajos realizados recientemente en el Bosque Pasochoa se han descubierto numerosas nuevas especies del género Drosophila. Los grupos de especies encontrados fueron repleta, tripunctata, mesophragmatica, guarani, flavopilosa y onnychophora $(1,2,3,4,5$ y 6$)$; estos hallazgos motivaron nuevos estudios en el bosque. Los resultados obtenidos revelan la existencia de 14 nuevas especies más del género Drosophila, 12 de ellas pertenecen a los grupos repleta, tripunctata, flavopilosa, guarani y annulimana, y 2 especies no agrupadas. El bosque Pasochoa es el único bosque andino del Ecuador en el que se han realizado estudios sobre la drosofauna. La diversidad de especies encontradas en el Pasochoa, nos estaría indicando la existencia de numerosos microhábitats y, sin ser pretenciosas, sospechamos que en el cráter del volcán existen aún más nuevas especies.

\section{MATERIALES Y MÉTODOS}

En el Bosque Pasochoa, localizado en las laderas del Volcán Pasochoa $\left(0^{\circ} 28^{\prime} \mathrm{S}, 78^{\circ}\right.$ $29^{\prime} \mathrm{W}$ ), se llevaron a cabo recolecciones de moscas del género Drosophila a lo largo de dos transectos de $1 \mathrm{~km}$ de longitud cada uno durante un año, desde marzo del 2001 hasta abril del 2002. El Transecto Uno (T1) va desde los 2780 a los $2850 \mathrm{msnm}$ y el Transecto Dos (T2) desde $\operatorname{los} 2900$ a los $3150 \mathrm{msnm}$; en cada transec- 
to se marcaron 21 puntos de recolección separados por $50 \mathrm{~m}$ uno de otro. La captura de moscas se realizó utilizando trampas de banano, las cuales permanecieron en el bosque por espacio de 5 a 15 días.

Para la identificación de las especies, se tomaron en cuenta sólo a los individuos machos, cada mosca fue analizada externamente, y la terminalia masculina fue sometida a ebullición en $\mathrm{KOH}$ por 10 minutos y luego disectada. El holotipo y paratipos de cada especie están depositados en el Museo de Zoología de la Pontificia Universidad Católica del Ecuador (QCAZ) en Quito.

\section{RESULTADOS}

\section{Grupo repleta}

D. shuyu sp. nov

(Figs. 1-5, 61)

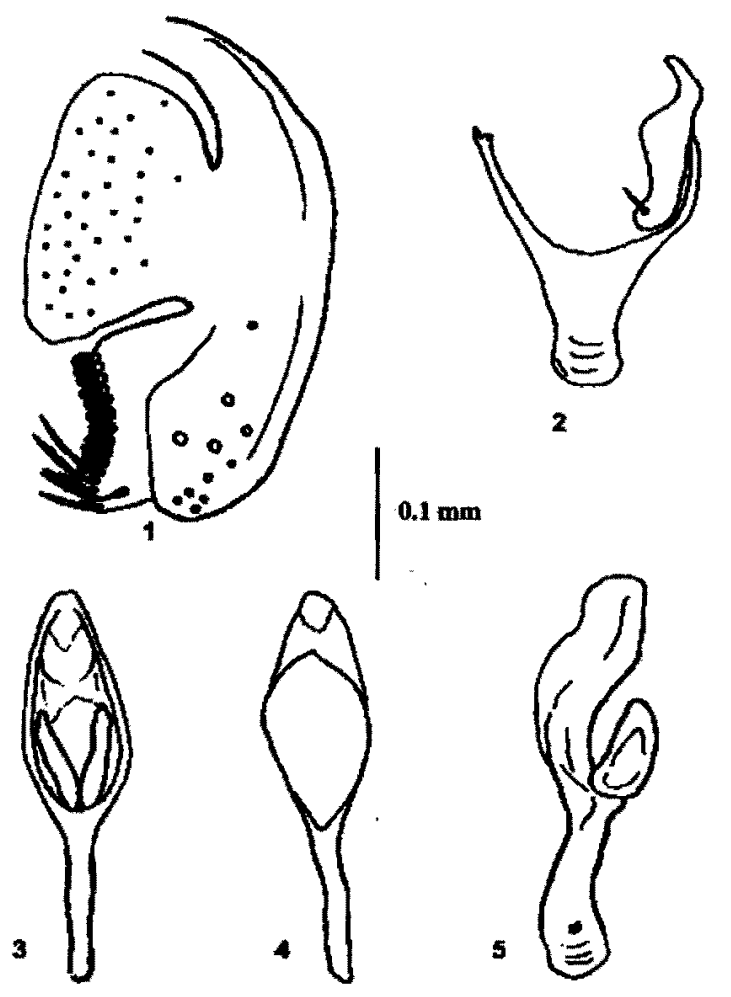

Figs. 1-5. Drosophila shuyu sp. nov. holotipo macho: 1, epandrio, placa anal y surestilo, vista posterior, lado izquierdo omitido; 2, hipandrio, vista posterior; 3-5, edeago, apodema del edeago y parafisis, vista ventral, dorsal y lateral izquierda respectivamente.
Material examinado. Holotipo $\delta$ (disectado y guardado en microtubo), etiquetado $D$. shuyu holotipo DVela det. 2003 / Pasochoa, Pichincha, Ecuador DVela $\delta$ col., jun. 2001. Un paratipo $\delta$ (disectado y guardado en microtubo), etiquetado $D$. shuy $u$ paratipo $O$ DVela det. 2003 / Pasochoa, Pichincha, Ecuador DVela col., mar. 2001. Un paratipo $\delta$ (disectado y guardado en microtubo), etiquetado $D$. shuyu paratipo $O$ DVela det. $2003 /$ Pasochoa, Pichincha, Ecuador DVela col., nov. 2001. Un paratipo ${ }^{\prime}$ (disectado y guardado en microtubo), etiquetado D. shuyu paratipo ODVela det. 2003 / Pasochoa, Pichincha, Ecuador DVela col., abr. 2002. Holotipo y paratipos depositados en QCAZ.

Localidad tipo. ECUADOR, Pichincha: Volcán Pasochoa, $35 \mathrm{~km}$ al sur de Quito.

Descripción. Cabeza de color marrón oscuro casi negro polinoso. Ocelos de color marrón oscuro, triângulo ocelar del mismo color que la cabeza. Ojos de color rojo oscuro. Orbital media es $1 / 2$ de la primera orbital y más cerca del ojo, cada cerda orbital nace de una mancha oscura. Carina prominente y levemente surcada. Una cerda oral prominente. Antena marrón, arista ramificada, con 3 ramas superiores, 2 ramas inferiores, más la bifurcación terminal y pequeñas ramificaciones internas. Longitud del cuerpo $2.1 \mathrm{~mm}$. Tórax de color marrón oscuro y polinoso con manchas oscuras que forma filas irregulares, de las cuales emergen los pelos acrosticales, ordenados en ocho filas frente a las cerdas dorsocentrales. Escutelo de color marrón oscuro. En las patas, la coxa y el fémur son de color marrón oscuro mientras que el tarso y metatarsos son de color marrón amarillento. Alas claras, longitud $2.6 \mathrm{~mm}$. Índice costal 2.3. Abdomen amarillento, del primero al tercer tergitos son completamente oscuros, algunas veces el borde superior es menos pigmentado. Del cuarto al sexto tergito se presenta la línea media dorsal dividiendo las bandas marginales en el centro del tergito. La pigmentación de estas bandas marginales cubre la mitad inferior del tergito.

Terminalia 0 . Placa anal fusionada al epandrio en la parte media. Surestilo con 14 dientes primarios, 9-10 cerdas marginales y 12 cerdas en la parte baja, 1 en la parte media y 3 en la parte superior del epandrio que presenta 
micropubescencia. Edeago quitinizado, en vista frontal es de forma ovalada y aguda en el ápice, el cual es menos quitinizado y con una ligera depresión en la punta; gonopodio desnudo y de forma semiovalada. Índice del edeago 1.3.

Etimología. "Shuyu" palabra del idioma quichua, que significa manchado. Esta especie presenta manchas en el tórax, característica típica de las especies del grupo repleta, y de algunas especies del grupo guarani (5).

\section{Grupo tripunctata}

\section{D. patacorona sp. nov.}

(Figs. 6-9, 62)

Material examinado. Holotipo $\delta$ (disectado y guardado en microtubo), etiquetado: $D$. patacorona ho-

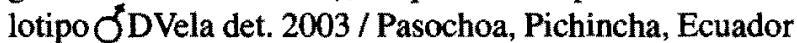
DVela col., mar. 2001. Un paratipo $\delta$ (disectado y guardado en microtubo), etiquetado $D$. patacorona paratipo DVela det. 2003 / Pasochoa, Pichincha, Ecuador DVela col., abr. 2001. Holotipo y paratipo depositados en QCAZ.

Localidad tipo. ECUADOR, Pichincha: Volcán Pasochoa, $35 \mathrm{~km}$ al sur de Quito.

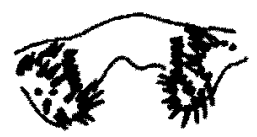

6

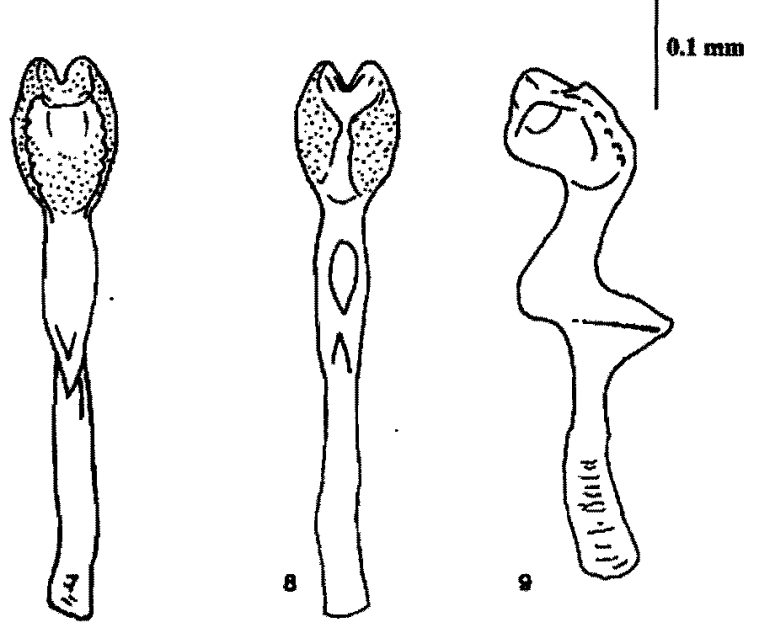

Figs. 6-9.Drosophila patacorona sp. nov. holotipo macho: 6 , surestilo, vista posterior; 7-9, edeago y apodema del edeago, vista ventral, dorsal y lateral izquierda respectivamente.
Descripción. Cabeza de color marrón claro polinoso. Ocelos de color blanco, triángulo ocelar más oscuro que la cabeza. Carina prominente. Una cerda oral. Arista con 4 ramas superiores, 2 ramas inferiores, más la bifurcación terminal y pequeñas ramificaciones internas. Longitud del cuerpo $3.2 \mathrm{~mm}$. Alas claras, longitud $3.6 \mathrm{~mm}$. Índice costal 3.5. Tórax de color marrón claro polinoso con 8 filas de pelos acrosticales. Patas amarillentas. Abdomen amarillento, del primero al quinto tergitos presencia de la línea dorsal media, las bandas marginales son de forma triangular y no llegan a los ángulos laterales del tergito; en el primero y segundo tergitos, a veces, las bandas pierden la forma y son apenas líneas engrosadas; el sexto tergito tiene una mancha en la parte central.

Terminalia $\delta$. Placa anal libre. Surestilo con 10-11 dientes primarios, 4 dientes secundarios y 8-9 cerdas marginales, $11-13$ cerdas en la parte baja del epandrio. Edeago quitinizado, en vista lateral se observa que la parte superior tiene una curvatura pronunciada, excrecencias laterales quitinizadas, ápice y zona central superior membranosa, la parte ventral cubierta por una membrana micropubescente, el ápice presenta una invaginación conspicua, abertura dorsal $1 / 5$ de la longitud total; gonopodio fusionado a las paráfisis y unido al edeago por tejido membranoso. Índice del edeago 0.88 .

Etimología. "Patacorona" palabra del idioma quichua, que significa meseta, Patacorona es una meseta del Volcán Pasochoa.

\section{D. quillu sp. nov.}

(Figs. 10-13, 63)

Material examinado. Holotipo $\delta$ (disectado y guardado en microtubo), etiquetado $D$. quillu holotipo JDVela det. 2003 / Pasochoa, Pichincha, Ecuador DVela col., mar. 2001. Cuatro paratipos $\delta$ (disectados y guardados en microtubos), etiquetados $D$. quillu paratipo $\delta$ DVela det. 2003 / Pasochoa, Pichin- 
cha-Ecuador DVela col., mar. 2001. Un paratipo (disectado y guardado en microtubo), etiquetado $D$. qui-

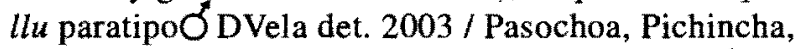
Ecuador DVela col., abr. 2001. Dos paratipos $\delta$ (disectados y guardados en microtubos), etiquetados $D$. quillu paratipo ? DVela det. 2003 / Pasochoa, Pichincha, Ecuador DVela col., jun. 2001. Dos paratipos (disectados y guardados en microtubos), etiquetados D. quillu paratipo ${ }^{6}$ DVela det. 2003 / Pasochoa, Pichincha, Ecuador DVela col., jul. 2001. Ocho paratipos $\delta$ (disectados y guardados en microtubos), etiquetados D. quillu paratipo ODVela det. 2003 / Pasochoa, Pichincha, Ecuador DVela col, abr. 2002. Holotipo y paratipos depositados en QCAZ.

Localidad tipo. ECUADOR, Pichincha: Volcán Pasochoa, $35 \mathrm{~km}$ al sur de Quito.

Descripción. Cabeza de color marrón claro, ocelos blancos, triángulo ocelar del mismo color que la cabeza. Ojos de color rojo brillante. Orbital media es $1 / 2$ o $1 / 3$ de la primera. Orbital media más cerca del ojo. Carina prominente. Una cerda oral prominente. Antena de

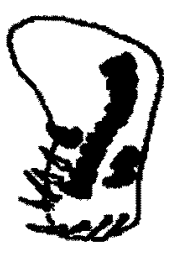

10

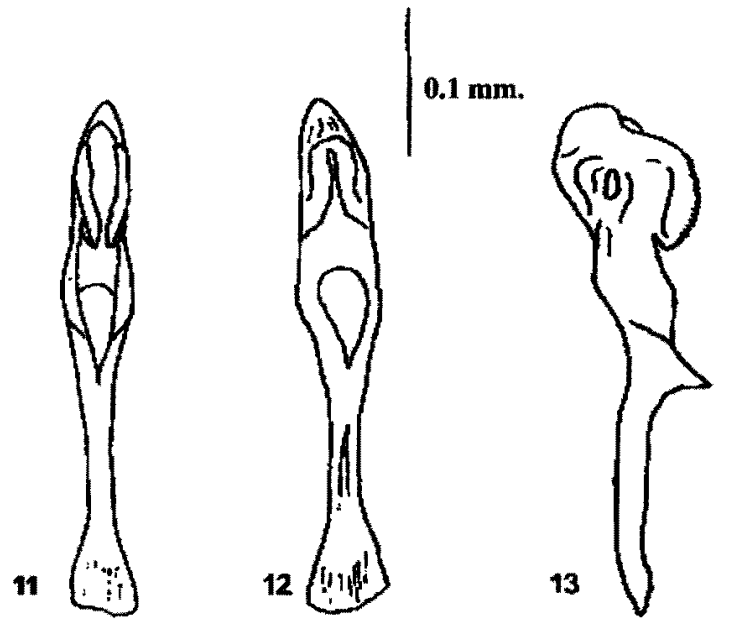

Figs. 10-13. Drosophila. quillu sp. nov. holotipo macho: 10, surestilo, vista posterior, lado izquierdo omitido; 11-13, edeago y apodema del edeago, vista ventral, dorsal y lateral izquierda respectivamente. color marrón claro, pubescente. Arista ramificada, con 5 ramas dorsales, 2 ramas ventrales, más la bifurcación terminal y pequeñas ramificaciones internas. Longitud del cuerpo $3.2 \mathrm{~mm}$. Tórax de color marrón claro polinoso, pelos acrosticales ordenados en siete $u$ ocho filas frente a las cerdas dorsocentrales. Escutelo de color marrón claro polinoso. Patas de color marrón claro ligeramente amarillentas. Alas claras, longitud $3.7 \mathrm{~mm}$. Índice costal 4.8. Abdomen amarillo pálido, presencia esporádica de línea dorsal media del primero al cuarto tergitos. El quinto y sexto tergitos presentan una banda oscura en el centro la cual no llega al borde superior.

Terminalia 6 . Placa anal libre. Surestilo con una fila de 13 dientes primarios, 2-5 dientes secundarios y 7-17 cerdas marginales, 2-6 cerdas en la parte baja y 1-2 cerdas en la parte media del epandrio. Edeago quitinizado, rama ventral de forma triangular, en vista lateral se observa la forma redondeada del edeago que en la parte central presenta una zona más quitinizada y de borde aserrado, abertura dorsal menos de 1/2 de la longitud del edeago; apodema ancho y menos quitinizado en la base. Índice del edeago 1.27 (1.12).

Etimología. "Quillu" palabra del idioma quichua que significa amarillo. Esta especie presenta coloración amarillenta en el abdomen y tórax.

\section{D. ninarumi sp. nov.}

(Figs. 14-17, 64)

Material examinado. Holotipo $\delta$ (disectado y guardado en microtubo) etiquetado $D$. ninarumi holotipo DVela det. 2003 / Pasochoa, Pichincha, Ecuador DVela col., abr. 2001. Un paratipo $\delta$, (disectado y guardado en microtubo), etiquetado D. ninarumi paratipo ODVela det. 2003 / Pasochoa, Pichincha, Ecuador DVela col., jun. 2001. Dos paratipos $\sigma$ (disectados y guardados en microtubos), etiquetados $D$. ninarumi paratipo $O$ DVela det. 2003 / Pasochoa, Pichincha, Ecuador DVela col., jul. 2001 . Un paratipo $\delta$ (disectado y guardado en microtubo), etiquetado $D$. ninarumi paratipo 6 DVela det. 2003 / Pasochoa, Pichincha, Ecuador DVela col., ene. 2002. Dos paratipos $\delta$ (disectados y guardados en microtubos), 
etiquetados D. ninarumi paratipo $\delta$ DVela det. $2003 /$ Pasochoa, Pichincha, Ecuador DVela col., feb. 2002. Holotipo y paratipos depositados en QCAZ.

Localidad tipo. ECUADOR, Pichincha: Volcán Pasochoa, 35 km. al sur de Quito.
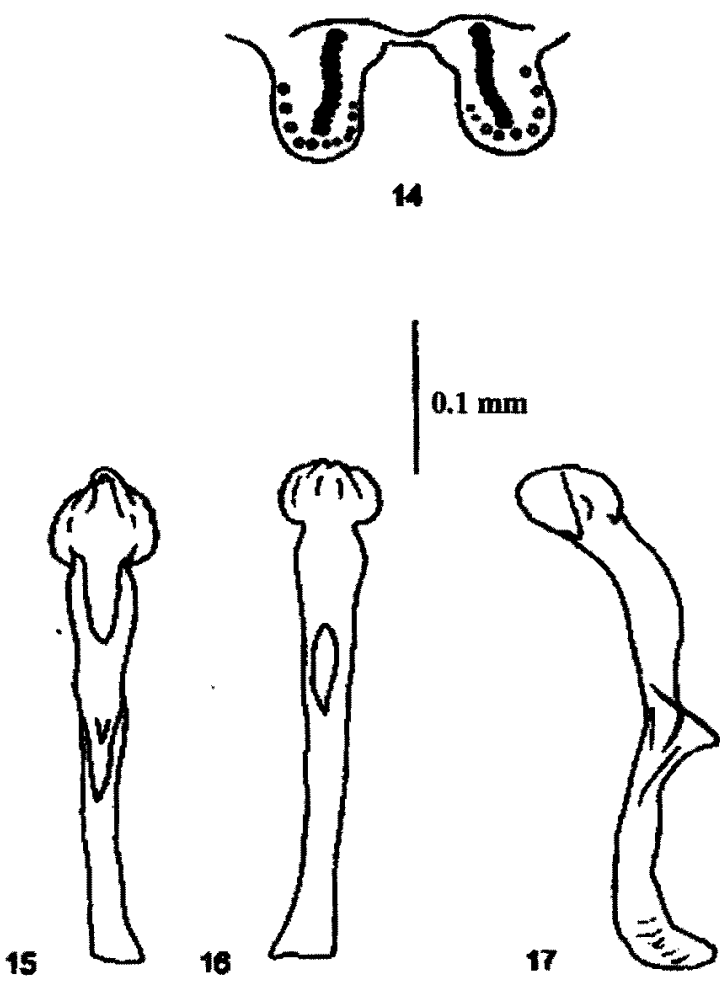

Figs. 14-17. Drosophila ninarumi sp. nov. holotipo macho: 14, surestilo, vista posterior; 15-17, edeago y apodema del edeago, vista ventral, dorsal y lateral izquierda respectivamente.

Descripción. Cabeza de color marrón claro, ligeramente polinosa. Ocelos transparentes, triángulo ocelar ligeramente más oscuro que la cabeza. Ojos de color rojo oscuro. Orbital media es $1 / 2$ de la primera, todas las cerdas orbitales están a la misma distancia del ojo. Carina prominente, una cerda oral prominente. Antena marrón, ligeramente más oscura que la cabeza. Arista ramificada, con 4 ramas dorsales y 2 ramas ventrales más la bifurcación terminal y pequeñas ramificaciones internas. Longitud del cuerpo $3.0 \mathrm{~mm}$. Tórax de color marrón claro polinoso, pelos acrosticales ordenados en ocho fi- las frente a las cerdas dorsocentrales. Escutelo de color marrón claro polinoso. Patas de color marrón amarillento. Alas claras, longitud $3.2 \mathrm{~mm}$. Índice costal 3.1. Abdomen amarillento, del primero al sexto tergitos presenta la línea dorsal media; el último tergito presenta la mitad inferior pigmentado, visto lateralmente los tergitos son obscuros y presentan áreas claras irregulares.

Terminalia $\delta$. Placa anal libre. Surestilo con una fila de 9-14 dientes primarios, sin dientes secundarios, 12-22 cerdas marginales y 2-4 cerdas en la parte baja y 1-2 cerdas en la parte media del epandrio. Edeago quitinizado y delgado, ápice semimembranoso, en vista ventral la cabeza tiene forma triangular con los bordes semiaserrados y el ápice membranoso y levemente bifurcado, abertura dorsal $1 / 4$ de la longitud total; el apodema presenta una curvatura hacia la parte ventral; gonopodio desnudo. Índice del edeago 0.82 (1.1). Relacionada con $D$. cuaso y $D$. triangulina.

Etimología. "Ninarumi" palabra del idioma quichua, que significa piedra incandescente, nombre de una pequeña loma cercana al Volcán Pasochoa.

\section{D. surucucho sp. nov.}

(Figs. 18-21, 65)

Material examinado. Holotipo $\delta$ (disectado y guardado en microtubo), etiquetado $D$. surucucho holotipo $\delta$ DVela det. 2003 / Pasochoa, Pichincha, Ecuador DVela col., abr. 2001. Dos paratipos $\delta$ (disectados y guardados en microtubos), etiquetados $D$. surucucho paratipo DVela det. 2003 / Pasochoa, Pichincha, Ecuador DVela col., abr. 2001. Dos paratipos $\delta$ (disectados y guardados en microtubos), etiquetados D. surucucho paratipo ODVela det. 2003 / Pasochoa, Pichincha, Ecuador DVela col., may. 2001. Dos paratipos $\delta$ (disectados y guardados en microtubos), etiquetados $D$. surucucho paratipo $\delta$ DVela det. 2003 / Pasochoa, Pichincha, Ecuador DVela col., jun. 2001. Tres paratipos $\delta$ (disectados y guardados en microtubos), etiquetados D. surucucho paratipo JDVela det. 2003 / Pasochoa, Pichincha, Ecuador DVela col., Jul. 2001. Holotipo y paratipos depositados en QCAZ. 


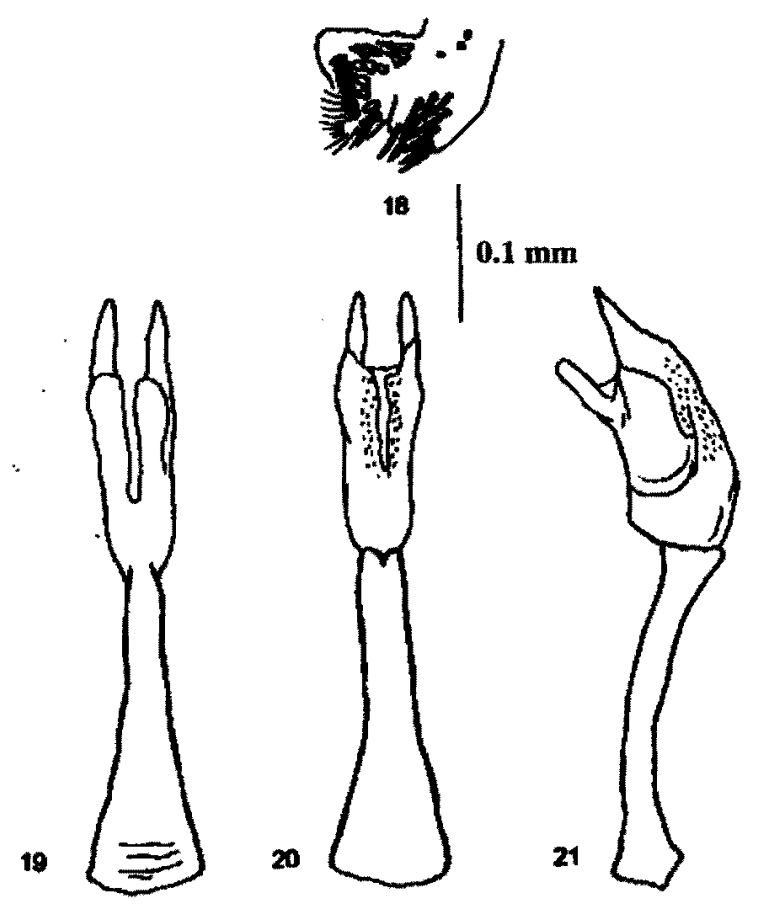

Figs. 18-21. Drosophila. surucucho sp. nov. holotipo macho: 18, surestilo, vista posterior, lado izquierdo omitido; 19-21, edeago, apodema del edeago y paráfisis, vista ventral, dorsal y lateral izquierda respectivamente.

Localidad tipo. ECUADOR, Pichincha: Volcán Pasochoa, 35 km. al sur de Quito.

Descripción. Cabeza de color marrón claro polinoso. Ocelos de color miel, triángulo ocelar de igual color que cabeza. Ojos rojos. Segunda orbital 1/3 de la primera, todas las cerdas orbitales a igual distancia del ojo. Carina muy prominente. Dos cerdas orales. Antena de color marrón claro, el tercer segmento más oscuro, Arista con 5 ramas superiores, 2 ramas inferiores más la bifurcación terminal y pequeñas ramificaciones internas. Longitud del cuerpo $3.0 \mathrm{~mm}$. Tórax marrón claro polinoso con $8 \mathrm{fi}$ las de pelos acrosticales. Patas amarillentas. Alas claras, longitud $3.0 \mathrm{~mm}$. Índice costal 4.1 . Abdomen amarillento, del primero al quinto tergitos presencia de línea dorsal media dividiendo las bandas marginales que son de forma triangular, en algunas ocasiones estas son muy delgadas y con apariencia de líneas verticales y en otros son triángulos que se extienden hacia los ángulos laterales, el sexto tergito tiene una franja en el centro.
Terminalia $\delta$. Placa anal libre. Surestilo con 9 dientes primarios, 10 dientes secundarios, 11-14 cerdas marginales, 8-9 cerdas en la parte inferior, 4 cerdas en la parte media del epandrio. Edeago quitinizado, alargado, ápice con dos proyecciones muy quitinizadas, la parte ventral membranosa y micropubescente; gonopodio semimembranoso con dos pequeñas cerdas en la parte distal, unido al edeago por tejido membranoso. Índice del edeago 0.96.

Etimología. "Surucucho" palabra del idioma quichua, que significa lugar o rincón donde crece el suro, planta del género Chuquea. Surucucho es una loma cercana al Pasochoa.

\section{D. ichubamba sp. nov.}

(Figs. 22-25, 66)

Material examinado. Holotip $\delta$ (disectado y guardado en microtubo), etiquetado $D$. ichubamba holotipo $\delta$ DVela det. 2003 / Pasochoa, Pichincha, Ecuador DVela col., may. 2001. Un paratipo ${ }^{\prime}$ (disectado y guardado en microtubos), etiquetado $D$. ichubamba paratipo $\delta$ DVela det. 2003 / Pasochoa, Pichincha, Ecuador DVela col., may. 2001. Dos paratipos ${ }^{\prime}$ (disectados y guardados en microtubos), etiquetados D. ichubamba paratipo O DVela det. $2003 / \mathrm{Pa}$ sochoa, Pichincha, Ecuador DVela col., abr. 2002. Holotipo y paratipos depositados en QCAZ.

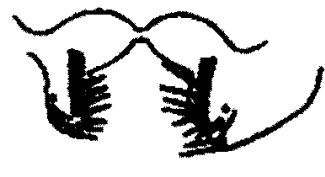

2

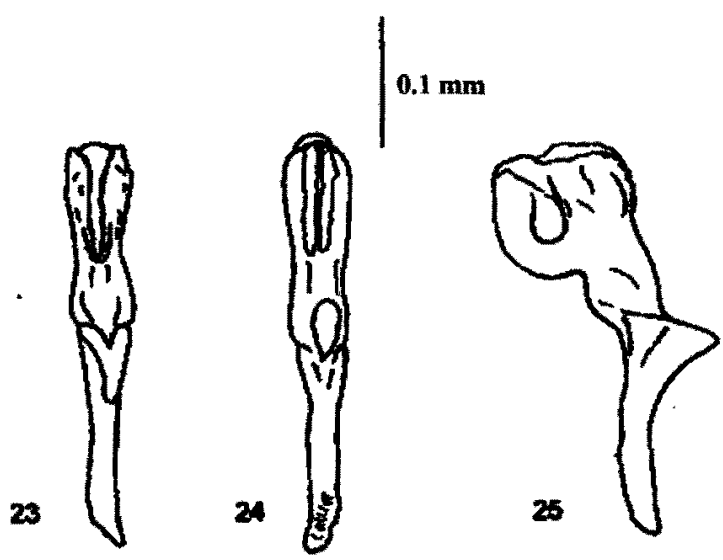

Figs. 22-25. Drosophila. ichubamba sp. nov. holotipo macho: 22 , surestilo, vista posterior; 23-25, edeago y apodema del edeago, vista ventral, dorsal y lateral izquierda respectivamente. 
Localidad tipo. ECUADOR, Pichincha: Volcán Pasochoa, 35 km. al sur de Quito.

Descripción. Cabeza de color marrón claro polinoso. Ocelos de color amarillento, con los bordes ligeramente más oscuros. Triángulo ocelar del mismo color que la cabeza. Ojos de color rojo. Orbital media es $1 / 2$ de la primera, todas a la misma distancia del ojo. Carina prominente. Una cerda oral prominente. Antena de color marrón claro. Arista con 5 ramas superiores y 2 ramas inferiores más la bifurcación terminal y pequeñas ramificaciones internas. Longitud del cuerpo $2.9 \mathrm{~mm}$. Tórax de color marrón claro polinoso, con 8 filas de pelos acrosticales. Escutelo del mismo color que el tórax, patas de color amarillento ligeramente polinoso. Alas claras, longitud $3.0 \mathrm{~mm}$. Índice costal 3.7. Abdomen amarillento, del primero al cuarto tergitos con una delgada banda oscura en el borde inferior; la línea dorsal media se presenta irregularmente en uno o varios tergitos dividiendo las bandas marginales; en el quinto y sexto tergitos se presenta una banda que cubre la mitad inferior del mismo.

Terminalia ơ. Placa anal libre. Epandrio con micropubescencia. Surestilo con una fila de 8-10 dientes primarios, sin dientes secundarios, 8-10 cerdas marginales, $2-3$ cerdas en la parte baja del epandrio y una cerda en la parte media. Edeago quitinizado, rama ventral de forma triangular, la parte superior del edeago es de forma redonda, la parte dorsal semimembranosa, en vista dorsal presenta una área transparente de forma circular; gonopodio con una cerda pequeña en la parte central y unido al edeago por tejido membranoso. Índice del edeago 1.22 .

Etimología. "Ichubamba" palabra quichua, que significa pajonal. Ichubamba es un cerro junto al Volcán Pasochoa.

\section{D. urcu sp. nov.}

(Figs. 26-29, 67)

Material examinado. Holotipo (disectado y guardado en microtubo), etiquetado $D$. urcu holotipo DVela det. 2003 / Pasochoa, Pichincha, Ecuador DVela col., abr. 2002, depositado en QCAZ.

Localidad tipo. ECUADOR, Pichincha: Volcán Pasochoa, 35 km. al sur de Quito.

Terminalia $\delta$. Placa anal libre, termina en una prolongación hacia el surestilo. Surestilo con 11-12 dientes primarios, 25-27 dientes secundarios en la parte externa del surestilo y 9 10 dientes en la parte interna del surestilo. 4-5 cerdas marginales, 3-4 cerdas en la parte baja del epandrio. Edeago quitinizado con una protuberancia quitinizada en la parte ventral, y la parte apical dorsal membranosa, con una hendidura muy pronunciada, la parte ventral recubierta por una membrana micropubescente. Índice del edeago 1.16.
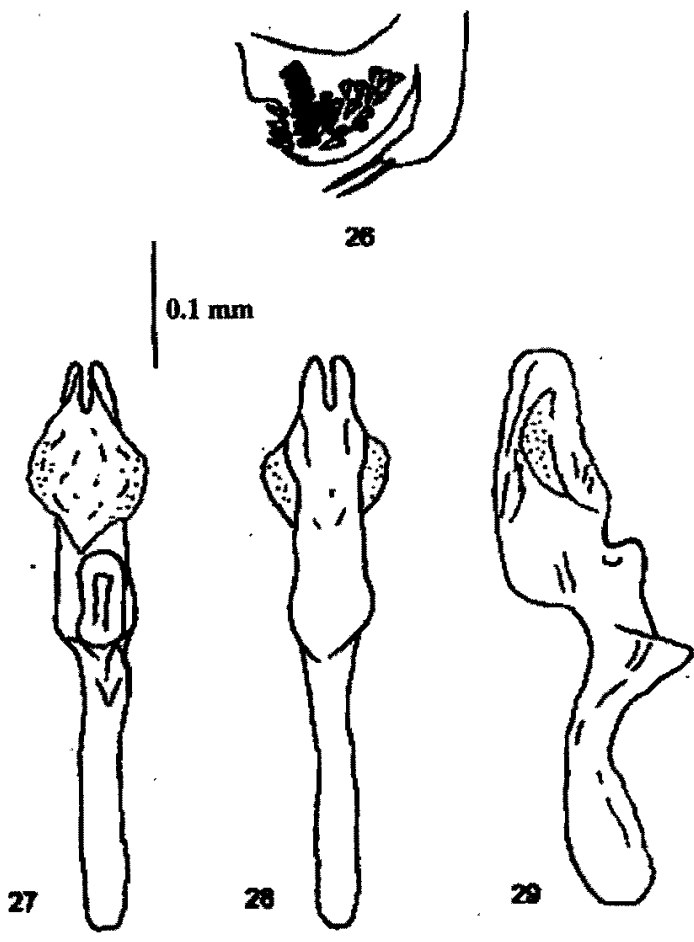

Figs. 26-29. Drosophila urcu sp. nov. holotipo macho: 26, surestilo, vista posterior, lado izquierdo omitido; $27-29$, edeago y apodema del edeago, vista ventral, dorsal y lateral izquierda respectivamente. 


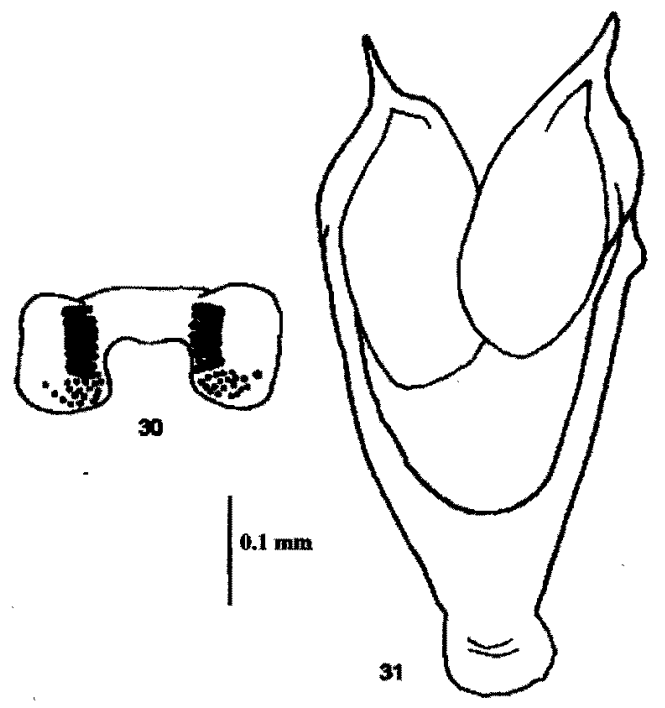

Figs. 30-31. Drosophila suni sp. nov. holotipo macho: 30, surestilo, vista posterior; 31 , hipandrio, vista posterior.

Etimología. "Urcu" palabra del idioma quichua que significa cerro, nombre de un cerro ubicado cerca al Volcán Pasochoa.

\section{Grupo flavopilosa}

D. suni sp. nov.

(Figs. 30-34, 68)

Material examinado. Holotipo (disectado y guardado en microtubo), etiquetado $D$. suni holotipo DVela det. 2003 / Pasochoa, Pichincha, Ecuador DVela col., mar. 2001, depositado en QCAZ.

Localidad tipo. ECUADOR, Pichincha: Volcán Pasochoa, 35 km. al sur de Quito.

Terminaliad. Placa anal fusionada. Epandrio pubescente. Surestilo micropubescente con 7-8 dientes primarios, sin dientes secundarios, 20-22 cerdas marginales, en la parte baja del epandrio numerosas cerdas muy largas. Edeago quitinizado, largo, ápice con bordes aserrados y una hendidura en el centro; apodema semiquitinizado y muy corto; gonopodio ovalado y alargado, con una cerda larga en la parte distal interna, unido al edeago por tejido membranoso. Índice del edeago 6.5 .

Etimología. "Suni" palabra quichua, que significa largo, característica que presenta el falo de esta especie.

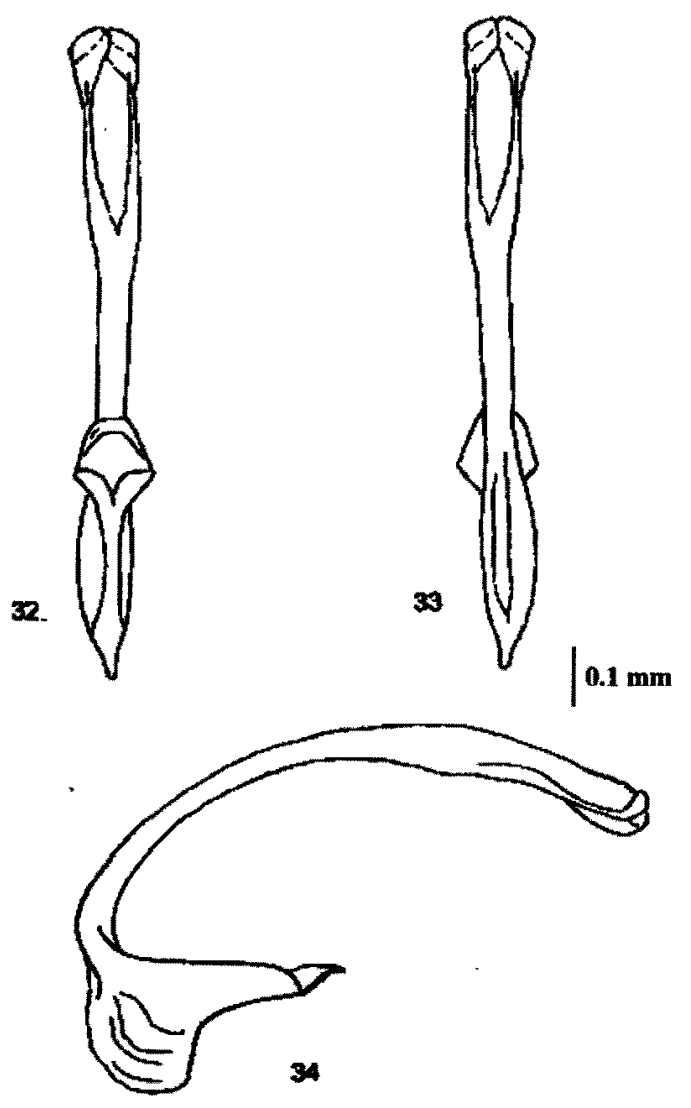

Figs. 32-34. Drosophila suni sp. nov. holotipo macho: 32-34, edeago, apodema del edeago y paráfisis, vista ventral, dorsal y lateral izquierda respectivamente.

\section{D. taxohuaycu sp. nov.}

(Figs. 35-39, 69)

Material examinado. Holotipo $\delta$ (disectado y guardado en microtubo), etiquetado D. taxohuaycu holotipo DVela det. 2003 / Pasochoa, Pichincha, Ecuador DVela col., mar. 2001. Un paratipo $\delta$ (disectado y guardado en microtubo), etiquetado $D$. taxohuaycu paratipo DVela det. 2003/Pasochoa, Pichincha-Ecuador DVela col., may.2001. Holotipo y paratipo depositados en QCAZ.

Localidad tipo. ECUADOR, Pichincha: Volcán Pasochoa, 35 km. al sur de Quito.

Descripción. Cabeza de color marrón oscuro. Ocelos blancos, triángulo ocelar de igual color que cabeza. Ojos rojos. Carina pronunciada, una cerda oral prominente. Tórax de color marrón oscuro polinoso. Patas de color amarillento. Alas transparentes. 
Terminalia $\delta$. Placa anal libre. Epandrio micropubescente. Surestilo micropubescente, con 13 dientes primarios, sin dientes secundarios, 11 cerdas marginales y 18 cerdas en la parte baja del epandrio. Hipandrio de forma de triángulo invertido, presenta dos cerdas en las paráfisis. Edeago quitinizado, ápice de forma triangular y asimétrico, un lado es más corto, curvado hacia la parte ventral, la región superior dorsal presenta prominencias de las que emergen microproyecciones, rama ventral larga; apodema ligeramente más quitinizado y más corto que el edeago; gonopodio de forma triangular con tres cerdas en la parte distal. Índice del edeago 2.07 .

Etimología. "Taxohuaycu” palabra quichua que significa quebrada del taxo, fruto del género Passiflora.
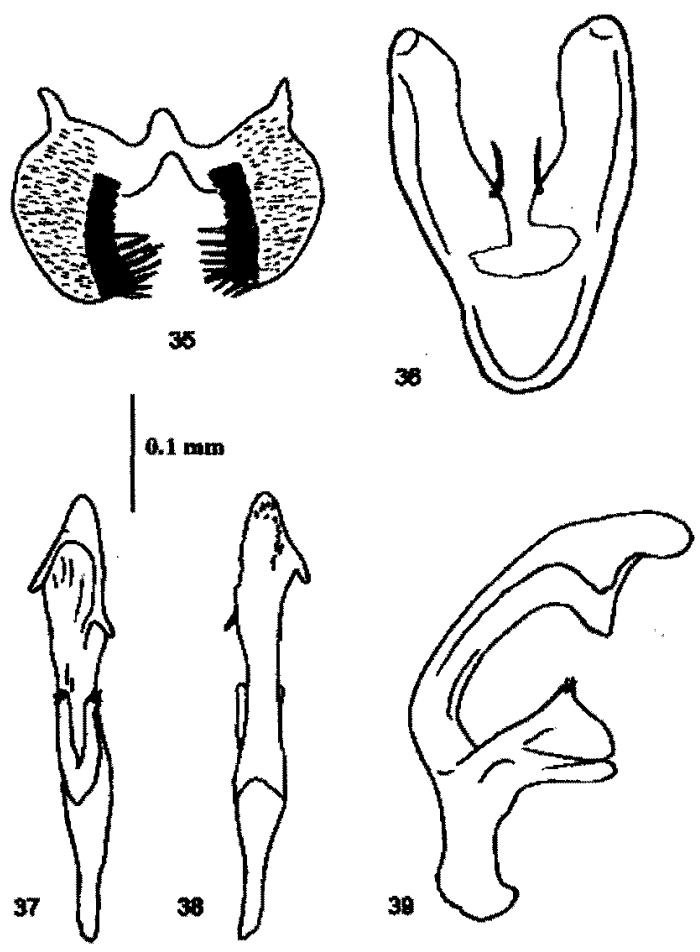

Figs. 35-39. Drosophila taxohuaycu sp. nov. holotipo macho: 35 , surestilo, vista posterior; 36 , hipandrio, vista posterior; 3739 , edeago, apodema del edeago y paráfisis, vista ventral, dorsal y lateral izquierda respectivamente.

\section{D. sisa sp. nov.}

(Figs. 40-44, 70)

Material examinado. Holotipo ó(disectado y guardado en microtubo), etiquetado $D$. sisa holotipo $O$ DVela det. 2003 / Pasochoa, Pichincha, Ecuador DVela col., abr. 2002. Un paratipo (disectado y guardado en microtubo), etiquetado D. sisa paratipo ODDVla det. 2003 / Pasochoa, Pichincha-Ecuador DVela col., abr. 2002. Holotipo y paratipo depositados en QCAZ.

\section{Localidad tipo. ECUADOR, Pichincha:} Volcán Pasochoa, $35 \mathrm{~km}$. al sur de Quito.

Descripción. Cabeza de color marrón brillante, ocelos blancos, triángulo ocelar ligeramente más oscuro que la cabeza. Primera orbital 1/3 de la primera, segunda y tercera orbital ligeramente más cerca del ojo. Carina prominente, no surcada, una cerda oral. Arista con 3 ramas superiores, 2 inferiores más la bifurcación terminal. Longitud del cuerpo $3.0 \mathrm{~mm}$. Tórax marrón polinoso, con 8 filas de pelos acros-
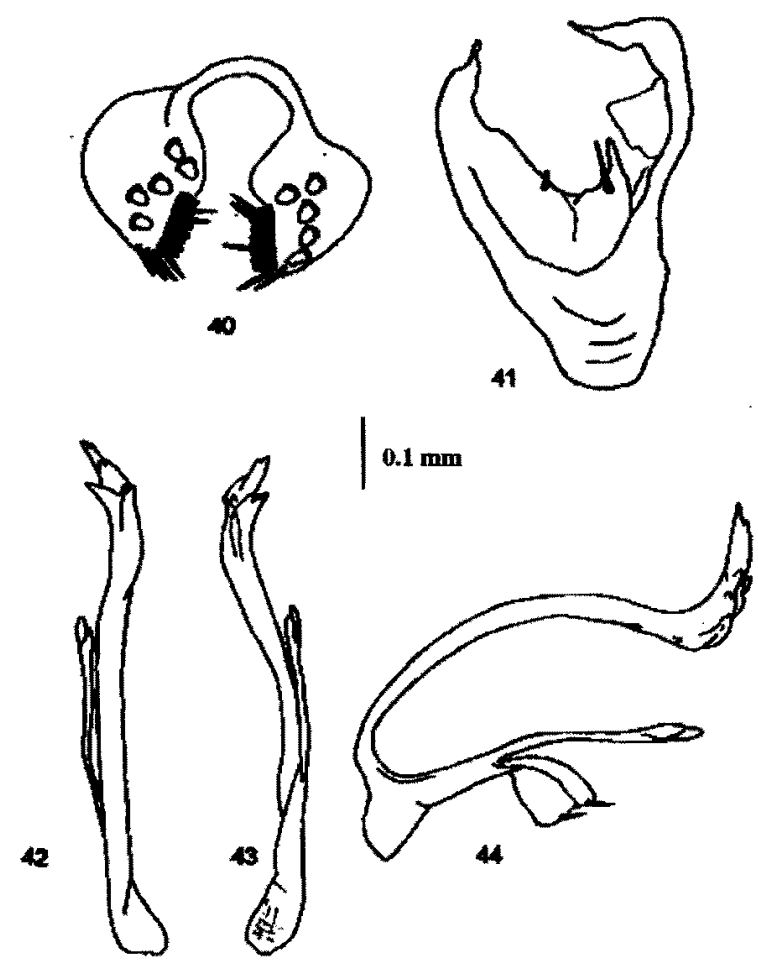

Figs. 40-44. Drosophila sisa sp. nov. holotipo macho: 40 , surestilo, vista posterior; 41 , hipandrio, vista posterior; $42-44$. edeago, apodema del edeago y paráfisis, vista ventral, dorsal y lateral izquierda respectivamente. 
ticales. Patas de color marrón claro. Punta del ala oscurecida, la sombra cubre la parte distal de las celdas marginal, submarginal, primera posterior y segunda posterior. Longitud de las alas $3.1 \mathrm{~mm}$. Índice costal 3.8. Abdomen amarillento, del primero al cuarto tergitos presencia de línea dorsal media que divide las bandas marginales, el quinto y sexto tergitos totalmente pigmentados.

Terminalia $\delta$. Placa anal libre. Surestilo con 8 dientes primarios, 5 dientes secundarios, 4-5 cerdas marginales, 15 dientes quitinizados $y$ redondeados en el epandrio inferior, una cerda pequeña ubicada hacia la parte terminal y 8 cerdas grandes, 2 cerdas en la parte media del epandrio. Edeago largo y quitinizado, la parte superior ancha y curvada hacia la parte dorsal, los bordes de la región superior se doblan hasta juntarse en el parte ventral, ápice con dos proyecciones laterales y más abajo del ápice se presentan cuatro proyecciones quitinizadas formando una especie de corona, la rama ventral del edeago es filiforme y termina en dos formaciones a manera de dedos; apodema membranoso y muy corto. Índice del edeago 7.58.

Etimología. "Sisa" palabra quichua que significa flor. El ápice del edeago de esta especie se asemeja a una flor.

\section{Grupo guarani}

D. cuscungu sp. nov.

(Figs. 45-48, 71)

Material examinado. Holotipo $\delta$ (disectado y guardado en microtubo), etiquetado $D$. cuscungu holotipo DVela det. 2003 / Pasochoa, Pichincha, Ecuador DVela col., jun. 2001, depositado en QCAZ.

Localidad tipo. ECUADOR, Pichincha: Volcán Pasochoa, 35 km. al sur de Quito.

Terminalia $\delta$. Placa anal libre, epandrio superior micropubescente. Surestilo con 10-11 dientes primarios, 3-4 dientes en la parte externa y 1-4 dientes en la parte interna del surestilo. 9-10 cerdas marginales, 8 cerdas en la parte ba- ja del epandrio y 1 cerda en la parte media. Edeago quitinizado, ensanchado y membranoso en la parte dorsal, rama ventral grande, el ápice con dos proyecciones quitinizadas y junto a ellas dos proyecciones membranosas y micropubescentes; apodema semiquitinizado; gonopodio fusionado a las paráfisis con dos cerdas pequeñas y una larga y gruesa. Índice del edeago 1.47 .

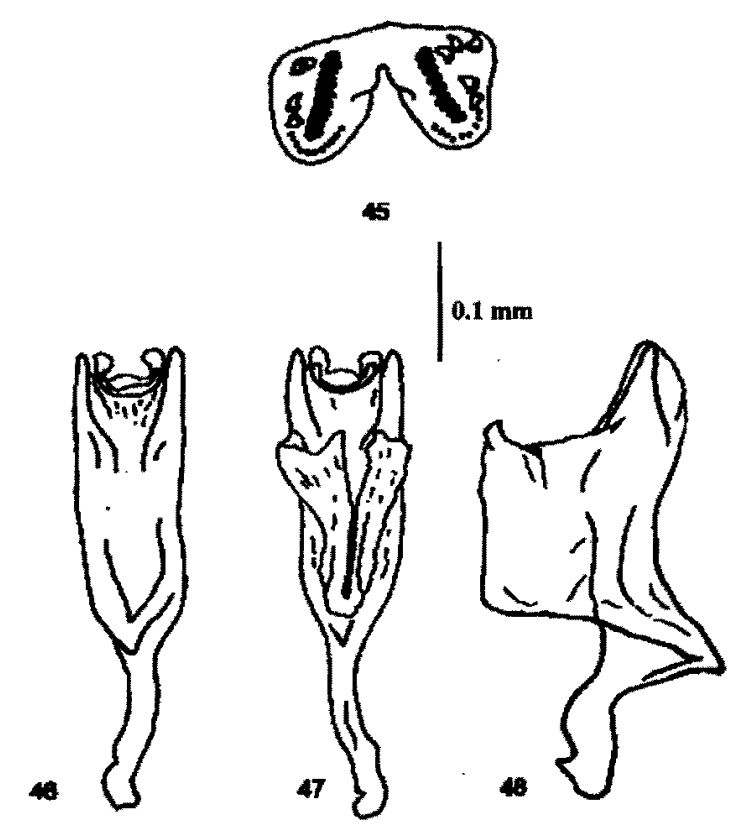

Figs. 45-48. Drosophila cuscungu sp. nov. holotipo macho: 45, surestilo, vista posterior; $46-48$, edeago y apodema del edeago, vista ventral, dorsal y lateral izquierda respectivamente.

Etimología. "Cuscungu" palabra del idioma quichua con que se nombra a los buhos de plumaje negro. Esta especie presenta coloración oscura.

\section{Grupo annulimana}

D. yana sp. nov.

(Figs. 49-52, 72)

Material examinado. Holotipo $\delta$ (disectado y guardado en microtubo), etiquetado $D$. yana holotipo DVela det. 2003 / Pasochoa, Pichincha, Ecuador DVela col., mar. 2001. Un paratipo ó (disectado y guardado en microtubo), etiquetado $D$. yana paratipo $\delta$ DVela det. 2003 / Pasochoa, Pichincha, Ecuador DVela col., may. 2001. Un paratipo $\delta$ (disectado y guardado en microtu- 
bo), etiquetado $D$. yana paratipo ${ }^{\circ}$ DVela det. 2003 / Pasochoa, Pichincha-Ecuador DVela col., nov. 2001. Holotipo y paratipos depositados en QCAZ.

Localidad tipo. ECUADOR, Pichincha: Volcán Pasochoa, $35 \mathrm{~km}$ al sur de Quito.

Descripción. Cabeza de color marrón oscuro. Ocelos blancos, triángulo ocelar marrón oscuro. Ojos rojo oscuro. Segunda cerda orbital $2 / 3$ de la primera y ligeramente más cerca del ojo. Carina prominente y surcada. Una cerda oral. Arista con 5 ramas superiores, 3 ramas inferiores más la bifurcación terminal y pequeñas ramificaciones internas. Longitud del cuerpo $3.9 \mathrm{~mm}$. Tórax marrón oscuro polinoso con franjas fusionadas que dejan pequeños espacios más claros y más polinosos, ocho filas de pelos acrosticales. Patas de color marrón oscuro. Alas con manchas en $\mathrm{r}-\mathrm{m}$ (vena transversal anteror) y dm-Cu (vena transversal posterior), las celdas marginal, submarginal y primera posterior, también están sombreadas, longitud $4.1 \mathrm{~mm}$. Índice costal 3.5. Abdomen marrón oscuro, cada
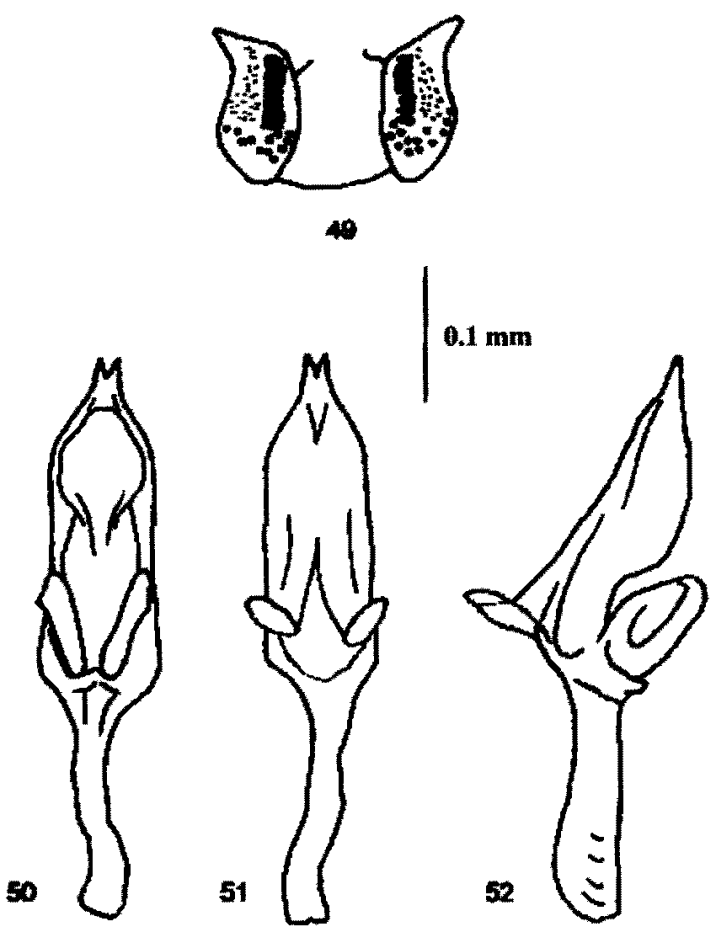

Figs. 49-52. Drosophila yana sp. nov. holotipo macho: 49, surestilo, vista posterior; 50-52, edeago, apodema del edeago y paráfisis, vista ventral, dorsal y lateral izquierda respectivamente. tergito con una banda vertical delgada en el centro, esta banda se adelgaza en los últimos tergitos.

Terminalia ${ }^{\circ}$. Placa anal fusionada. Epandrio pubescente. Surestilo con 10-11 dientes primarios, sin dientes secundarios, $9-10$ cerdas marginales, 16-17 cerdas en la parte baja del epandrio 1-2 cerdas en la parte media y 1-2 cerdas en la parte superior del epandrio. Edeago quitinizado con dos proyecciones laterales en la parte dorsal, ápice delgado y bífido; apodema delgado con una pequeña cerda y micropubescencia en la parte central; gonopodio semiovalado y unido al edeago por tejido membranoso. Índice del edeago 1.14.

Etimología. "Yana" palabra del idioma quichua para nombrar cualquier cosa de coloración negra. Esta especie es de coloración casi negro.

\section{Especies no agrupadas \\ D. condormachay sp. nov.}

(Figs. 53-56, 73)

Material examinado. Holotipo $\delta$ (disectado y guardado en microtubo), etiquetado $D$. condormachay holotipo DVela det. 2003 / Pasochoa, Pichincha, Ecuador DVela col., jun. 2001. Un paratipo $\delta$ (disectado y guardado en microtubo), etiquetado $D$. condormachay paratipo DVela det. 2003 / Pasochoa, Pichincha, Ecuador DVela col., ago. 2001. Dos paratipos $\sigma$ (disectados y guardados en microtubos), etiquetados $D$. condormachay paratipo DV DVla det. 2003 / Pasochoa, PichinchaEcuador DVela col, sep. 2001. Dos paratipos $\delta$ (disectados y guardados en microtubos), etiquetados $D$. condormachay paratipo O DVela det. 2003 / Pasochoa, Pichincha-Ecuador DVela col., oct. 2001. Holotipo y paratipos depositados en QCAZ.

Localidad tipo. ECUADOR, Pichincha: Volcán Pasochoa, 35 km al sur de Quito.

Descripción. Cabeza de color marrón claro polinoso. Ocelos transparentes, triángulo ocelar del mismo color que cabeza. Ojos rojos. Segunda orbital 2/3 de la primera. Carina prominente y surcada, una cerda oral prominente. Antena micropubescente. Tórax marrón claro polinoso, cerdas preescutelares. Patas amari- 
llentas. Alas con manchas en r-m (vena transversal anterior) y dm-Cu (vena transversal posterior), las celdas marginales, submarginal y primera posterior bastante sombreadas. Abdomen amarillo grisáceo, bandas oscuras en la línea media dorsal y en los bordes superior e inferior de cada tergito.

Terminalia o. Placa anal fusionada. Epandrio microopubescente. Surestilo micropubescente, con 12-13 dientes primarios, sin dientes secundarios, 7-8 cerdas marginales, 28 cerdas en la parte baja del epandrio y 3 en la parte superior. Edeago quitinizado, con dos pequeñas proyecciones quitinizadas en la parte superior dorsal, ápice con una ligera hendidura; gonopodio de forma semicircular con una cerda en la parte distal. Índice del edeago 1.05 .
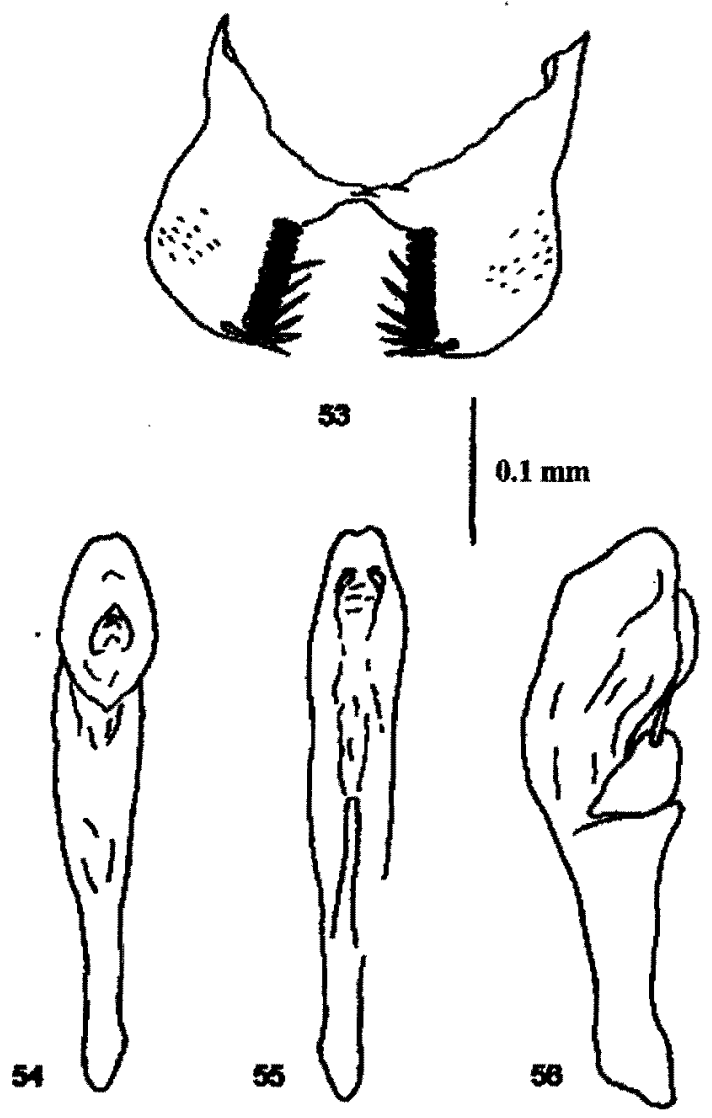

Figs. 53-56. Drosophila condormachay sp, nov. holotipo macho: 53, surestilo, vista posterior; 54-56, edeago, apodema del edeago y parafisis, vista ventral, dorsal y lateral izquierda respectivamente.
Etimología. Palabra del idioma quichua, que significa cueva del cóndor. "Condor Machay" es nombre de un peñasco cercano al Volcán Pasochoa.

\section{D. pugyu sp. nov.}

(Figs. 57-60, 74)

Material examinado. holotipo $\delta$ (disectado y guardado en microtubo), etiquetado $D$. pugyu holotipo DVela det. 2003 / Pasochoa, Pichincha, Ecuador DVela col., oct. 2001 depositado en QCAZ.

Localidad tipo. ECUADOR, Pichincha: Volcán Pasochoa, $35 \mathrm{~km}$ al sur de Quito.

Terminalia $\delta$. Placa anal fusionada. Surestilo con15-16 dientes primarios, sin dientes secundarios, 11 cerdas marginales, en la parte baja del epandrio 2 cerdas pequeñas y 8 cerdas grandes, epandrio pubescente. Edeago delgado y quinitizado con dos pequeñas proyeccio-
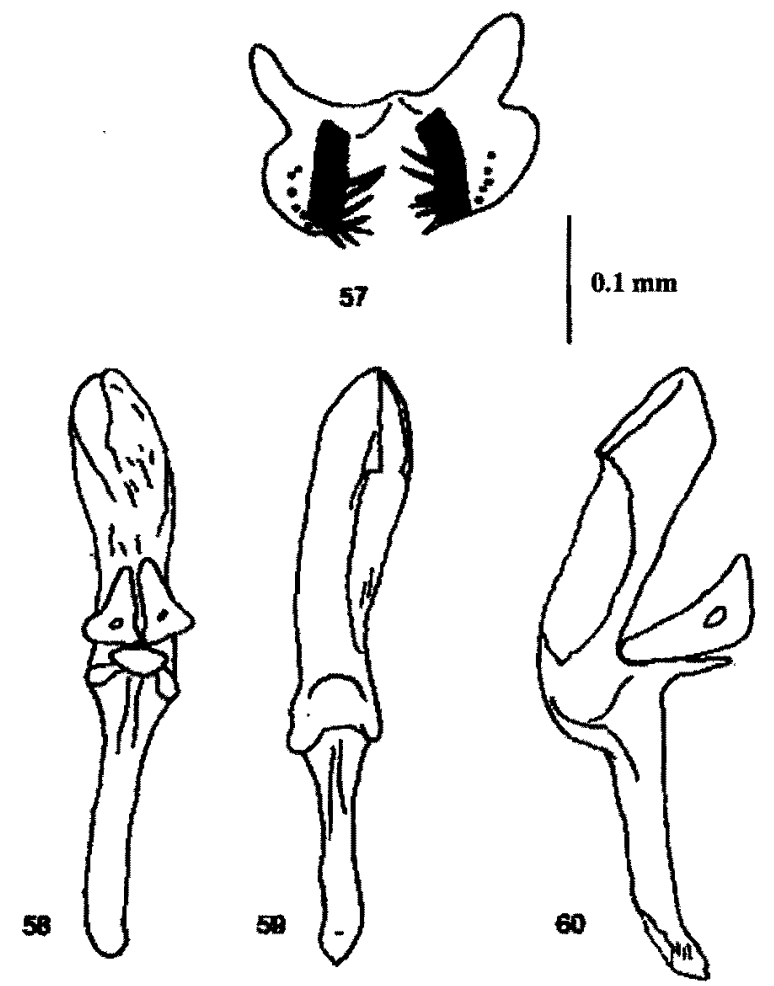

Figs. 57-60. Drosophila pugyu sp. nov. holotipo macho: 57, surestilo, vista posterior; 58-60, edeago, apodema del edeago y paráfisis, vista ventral, dorsal y lateral izquierda respectivamente. 
nes quitinizadas en la parte dorsal, rama ventral larga casi de igual longitud que el gonopodio; gonopodio desnudo, Índice del edeago 1.

Etimología. "Pugyu" palabra del idioma quichua, que significa fuente de agua, o manantial.

Agradecimientos. A nuestros colegas Anita Mafla y Geovani Onore por sus críticas y sugerencias, A IDEA WILD por la donación del material entomólogico. Este trabajo es parte del proyecto "Biodiversidad del género Drosophila y detección del impacto ambiental en el Refugio de vida Silvestre Pasochoa" y "Caracterización de nuevas especies ecuatorianas de Drosophila" financiado por la Pontificia Universidad Católica del Ecuador.

\section{REFERENCIAS}

1.- VeLA, D, y RAFAEL, V. Ocho nuevas especies del grupo tripunctata, género Drosophila (Diptera, Drosophilidae) y el registro de D. paraguayensis en el Bosque Protector Pasochoa, Pichincha-Ecuador. Revista de la Pontificia Universidad Católica del Ecuador, Quito, 2001; 66:91-120.

2.- VelA, D. y RAFAel, V. Estudios sobre la diversidad del género Drosophila (Diptera, Drosophilidae) en el Bosque Pasochoa de la Provincia de Pichincha-Ecuador. Revista de la Pontificia Universidad Católica del Ecuador, Quito, $2003 ; 71: 117-127$.

3.- VELA, D. \& RAFAEL, V. Three new Andean species of Drosophila (Diptera, Drosophilidae) of the mesophragmatica group. Iheringia, Sér. Zool., Porto Alegre, 2004; 94(3):295-299.

4.- VELA, D. y RAFAEL, V. Dos nuevas especies del grupo flavopilosa, género Drosophila (Diptera, Drosophilidae) en el Bosque Pasochoa. Provincia de Pichincha. Revista Ecuatoriana de Medicina y Ciencias Biológicas, de la Casa de la Cultura Ecuatoriana, 2004; 26(1,2):7-13.

5.- VELA, D. y RAFAEL, V. Tres nuevas especies del grupo guarani, género Drosophila (Diptera, Drosophilidae) en el Bosque Pasochoa, Provincia de Pichincha. Revista Ecuatoriana de Medicina y Ciencias Biológicas, de la Casa de la Cultura Ecuatoriana, 2004; $26(1,2): 14-21$.

6.- VELA, D. y RAFAEL, V. Nuevas especies de Drosophila (Diptera, Drosophilidae) en el Bosque Pasochoa, Pichincha-Ecuador. Revista de la Pontificia Universidad Católica del Ecuador, Quito, 2005, 75: 69-80. 


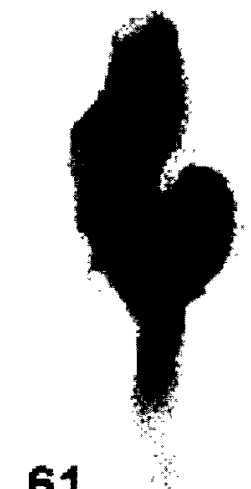

61
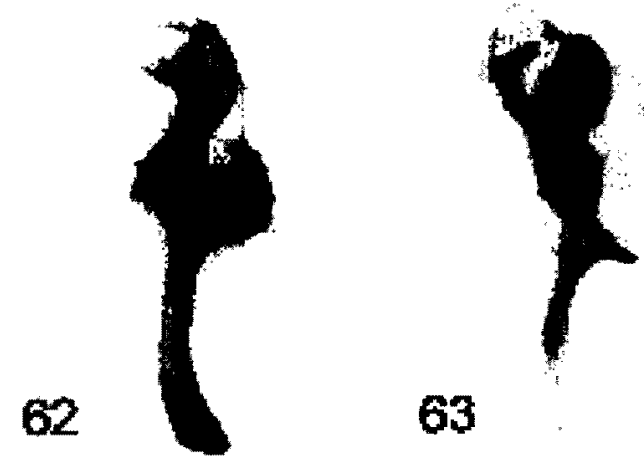

64
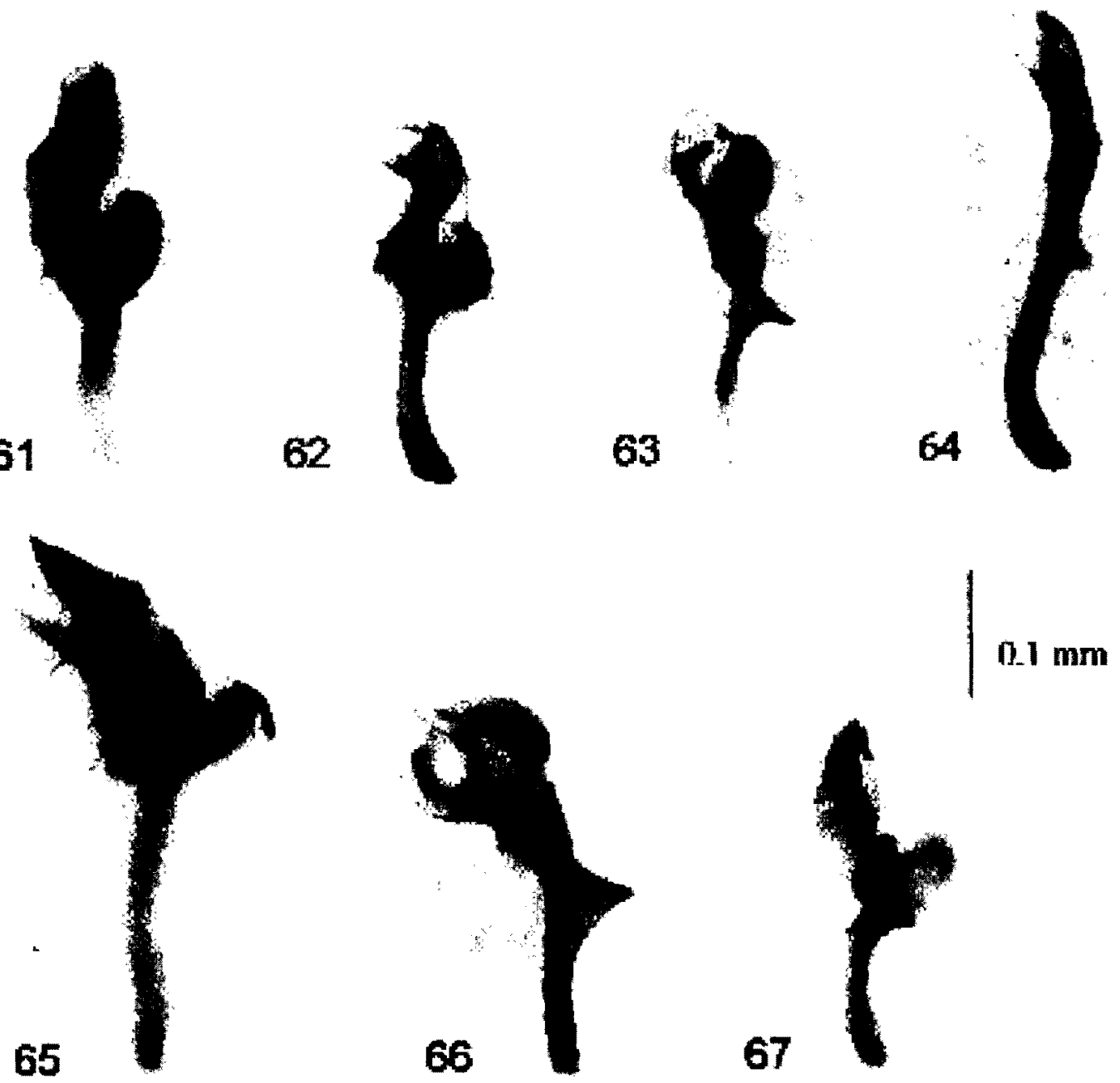

$0.1 \mathrm{~mm}$

\section{7}

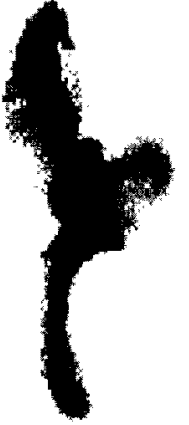

$+1$

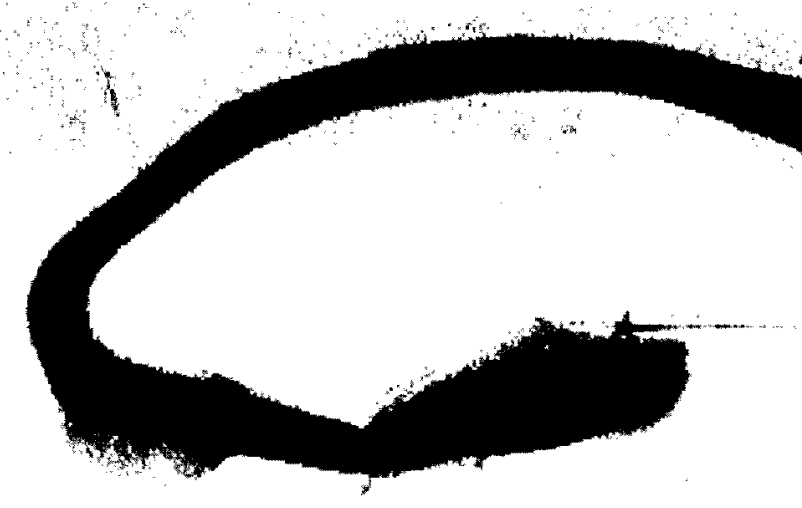

68

\section{$0.1 \mathrm{~mm}$}

Figs. 61-68. Edeago y apodema del edeago, vista lateral izquierda: 61, Drosophila shuyu sp. nov.; 62, Drosophila patacorona sp. nov.; 63, Drosophila quillu sp. nov; 64, Drosophila ninarumi sp. nov.; 65, Drosophila surucucho sp. nov.; 66, Drosophila ichubamba sp. nov; 67, Drosophila urcu sp. nov.; 68, Drosophila suni sp. nov. 


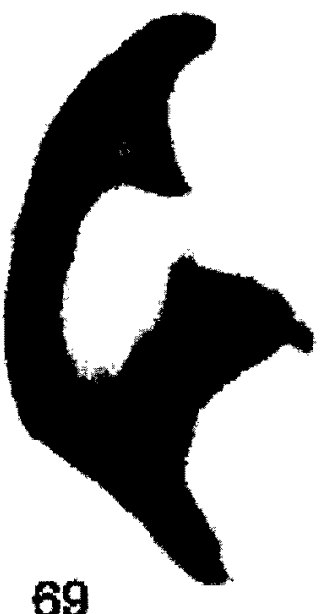

69

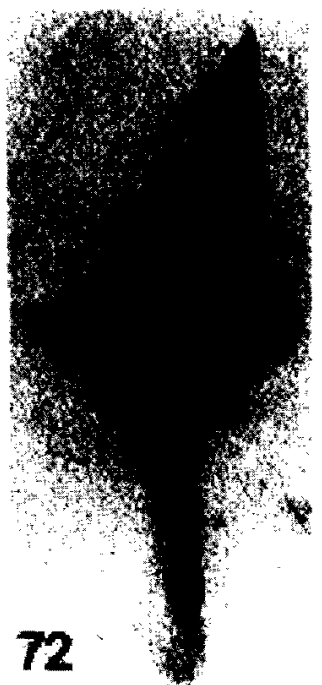

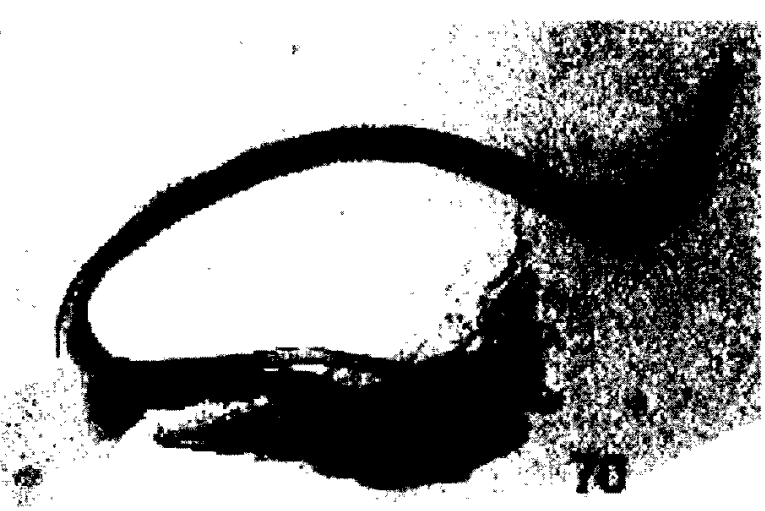

73

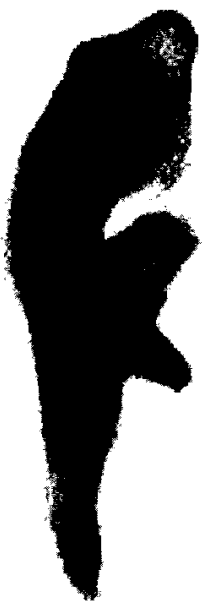

74

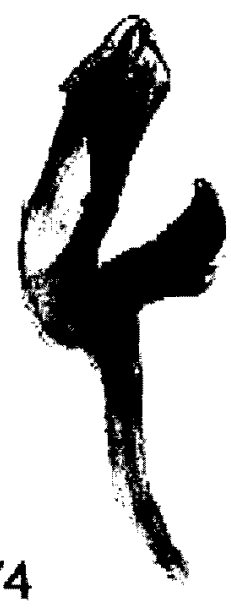

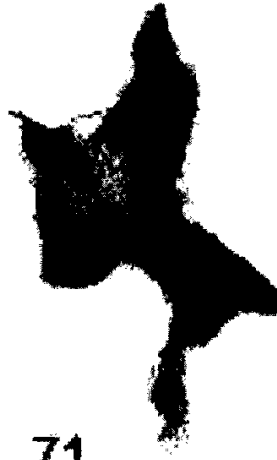

71

$0.1 \mathrm{~mm}$

Figs. 69-74. Edeago y apodema del edeago, vista lateral izquierda: 69, Drosophila taxohuaycu sp. nov.; 70, Drosophila sisa sp. nov.; 71, Drosophila cuscungu sp. nov.; 72, Drosophila yana sp. nov.; 73, Drosophila condormachay sp. nov. y 74, Drosophila pugyu sp. nov. 